Check for updates

Cite this: Chem. Commun., 2021, 57,219

Received 3rd November 2020,

Accepted 26th November 2020

DOI: $10.1039 / \mathrm{d} 0 \mathrm{cc} 07260 \mathrm{e}$

rsc.li/chemcomm

\section{Insight into the organocatalytic arylation of azonaphthalenes with $\alpha$-chloroaldehydes: the general mechanism and origin of selectivities $\dagger$}

\author{
Xinghua Wang, (D) ${ }^{a}$ Yang Wang, (D ${ }^{b}$ Donghui Wei (D) *a and Yu Lan (D) *a
}

\begin{abstract}
A systemical computational study was performed to explore the mechanism and origin of selectivities on the organocatalytic arylation of azonaphthalenes with $\alpha$-chloroaldehydes. The calculated results reveal that the nucleophilicity of active sites and the hydrogen bonds respectively regulate chemo- and stereoselectivities and, for the first time, N-heterocyclic carbene (NHC) can act as a multiple functional base (MFB) catalyst in one system.
\end{abstract}

Transition-metal-catalyzed inert aryl C-H activation/functionalization has been widely investigated as a powerful method for carboncarbon $(\mathrm{C}-\mathrm{C})$ and carbon-heteroatom $(\mathrm{C}-\mathrm{X})$ bond formation. In transition-metal-catalyzed aryl $\mathrm{C}-\mathrm{H}$ activation and transformation, aromatic rings generally act as formal electrophiles to react with different nucleophiles. ${ }^{1,2}$ However, nucleophilic aromatic substitution involving aryl $\mathrm{C}-\mathrm{H}$ cleavage, especially organocatalytic arylation, has been rarely reported. Nicewicz and co-workers were the first to report aryl $\mathrm{C}-\mathrm{H}$ amination and cyanation by direct $\mathrm{C}-\mathrm{H}$ functionalization using an acridinium photoredox organocatalyst. ${ }^{3,4}$ Subsequently, owing to the advantages of high stereoselectivity and low toxicity, organocatalytic arylations have attracted increasing attention and become one of the greatest challenges in the organocatalysis field..$^{5-8}$

Organocatalytic arylation of azonaphthalenes has been reported in a few experimental studies since 2017 (Scheme 1). ${ }^{9-12}$ In a pioneering study, Tan performed chiral phosphoric acid catalyzed enantioselective [3+2] annulation of azonaphthalenes with 2-substituted indoles to construct benzindole derivatives (Scheme 1A). ${ }^{9}$ Independently, Shi et al. reported chiral phosphoric acid catalyzed $[3+2]$ annulation of azonaphthalenes with azlactones (Scheme 1B). ${ }^{10}$

\footnotetext{
${ }^{a}$ Green Catalysis Center, and College of Chemistry, Zhengzhou University, Zhengzhou, Henan 450001, China. E-mail: donghuiwei@zzu.edu.cn, lanyu@cqu.edu.cn

${ }^{b}$ Department of Material and Chemical Engineering, Zhengzhou University of Light Industry, 136 Science Avenue, Zhengzhou, Henan Province, 450002, P. R. China $\dagger$ Electronic supplementary information (ESI) available: Computational details, energy profile of other possible pathways; Cartesian coordinates, energies of all the stationary points; and imaginary frequencies of transition states. See DOI: 10.1039/d0cc07260e
}

In addition, Li et al. found that a secondary amine can also catalyze the $[3+2]$ annulation of azonaphthalenes with enolizable carbonyl compounds (Scheme 1C). ${ }^{11}$ Note that Wang et al. reported unexpected [4+2] rather than [3+2] annulation of azonaphthalenes with $\alpha$-chloroaldehydes catalyzed by $\mathrm{N}$-heterocyclic carbene (NHC) (Scheme 1D). ${ }^{12}$ Although these excellent experimental reports greatly contributed to the determination of the possible mechanisms of these types of organocatalytic annulation reactions of azonaphthalenes, to the best of our knowledge, no systematic theoretical study of the possible mechanisms has been reported, and the origin of chemoselectivity and stereoselectivity remains unclear.

The above issue and our continuous interest in organocatalysis prompted us to perform a theoretical study, ${ }^{13-20}$ in which the NHC-catalyzed [4+2] annulation reaction of azonaphthalene with $\alpha$-chloroaldehyde was selected as the computational model
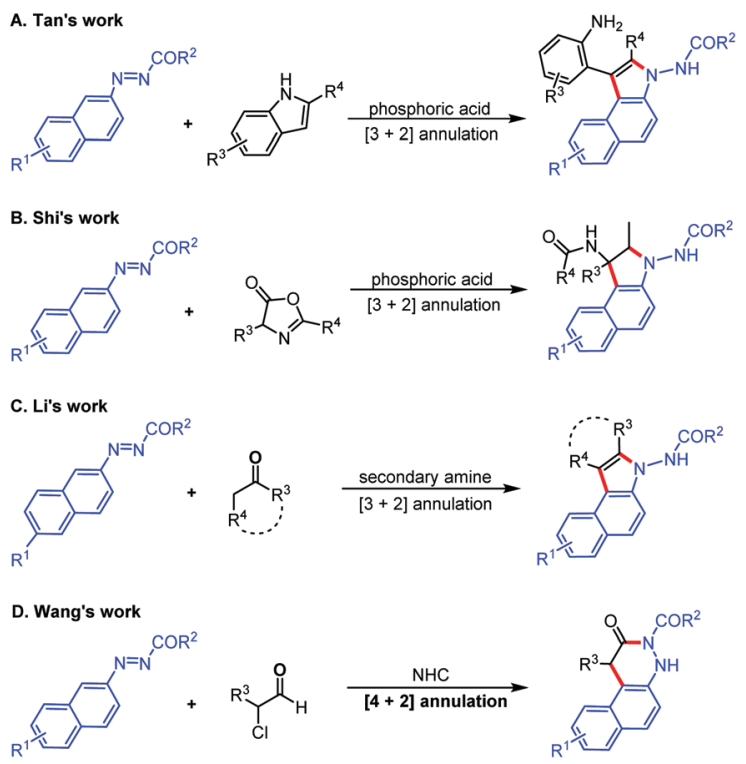

Scheme 1 Organocatalyst-mediated arylation reactions of azonaphthalenes. 


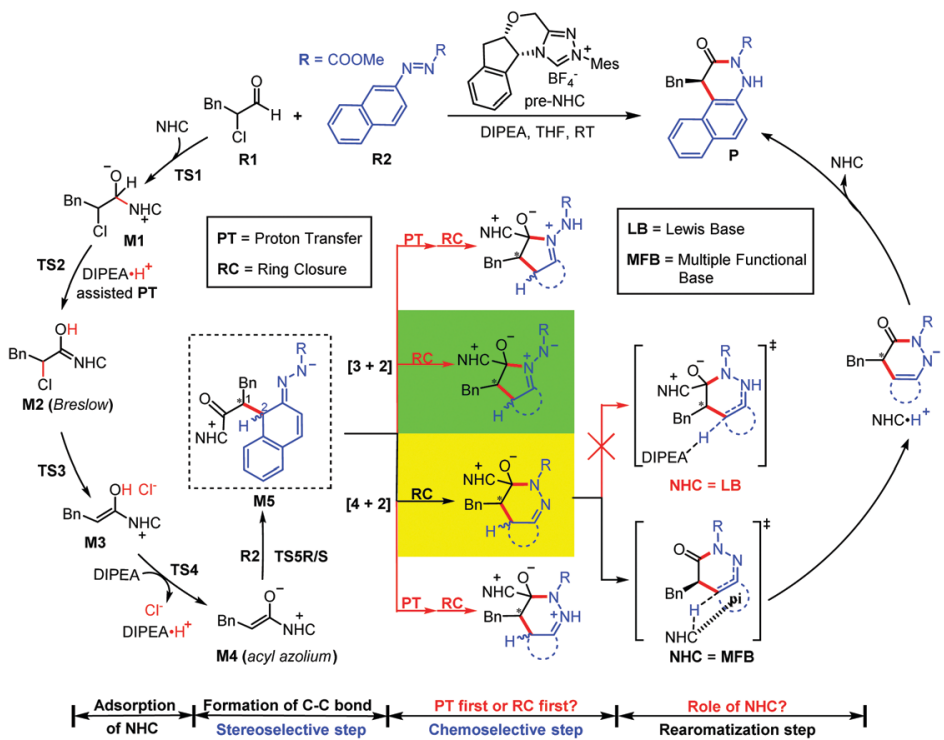

Scheme 2 Selected NHC-catalyzed reaction model with the unresolved questions.

(Scheme 2). In the present study, we aim to answer the following questions: (1) what is the detailed mechanism of this reaction? Four possible $[n+2](n=3,4)$ annulation pathways were considered for the chemoselective annulation step: two ringclosure (RC) first and two proton transfer (PT) first mechanisms. (2) What is the origin of the high stereoselectivity? The $R$ - and $S$-configured pathways in the stereoselective C-C bond formation process were calculated. (3) What is the role of the NHC catalyst in the whole reaction? For the first time, we propose that NHC can act as a multiple functional base (MFB, i.e. Lewis base, Brønsted base (BB) and hydrogen bond donor/acceptor) to promote the rearomatization process, which is remarkably different from the traditional role of the NHC catalyst as a Lewis base (LB) in one system. Due to the reliability of density functional theory (DFT) on the mechanistic studies of organocatalytic ${ }^{21-26}$ and transition metal-catalyzed reactions, ${ }^{27-30}$ we performed DFT calculations at the M06-2 $\mathrm{X}^{31,32}$ / 6-311++G(2df,2pd)/IEF-PCM THF $^{33,34 / / M 06-2 X / 6-31 G(d, p) / I E F-P C M ~}{ }_{\mathrm{THF}}$ level to investigate the detailed mechanism, the role of NHC, and the origin of selectivities. More computational details and a benchmark study are provided in the ESI. $\dagger$

As shown in Fig. 1, the whole reaction is initiated by nucleophilic addition to $\alpha$-chloroaldehyde $\mathbf{R} \mathbf{1}$ by the NHC obtained by the deprotonation of pre-NHC to generate zwitterionic intermediate M1 via the transition state TS1. With the aid of DIPEA $\mathrm{H}^{+}$, intermediate M1 transforms to Breslow intermediate M2 through $[1,2]$-proton transfer via transition state TS2. Owing to the attack

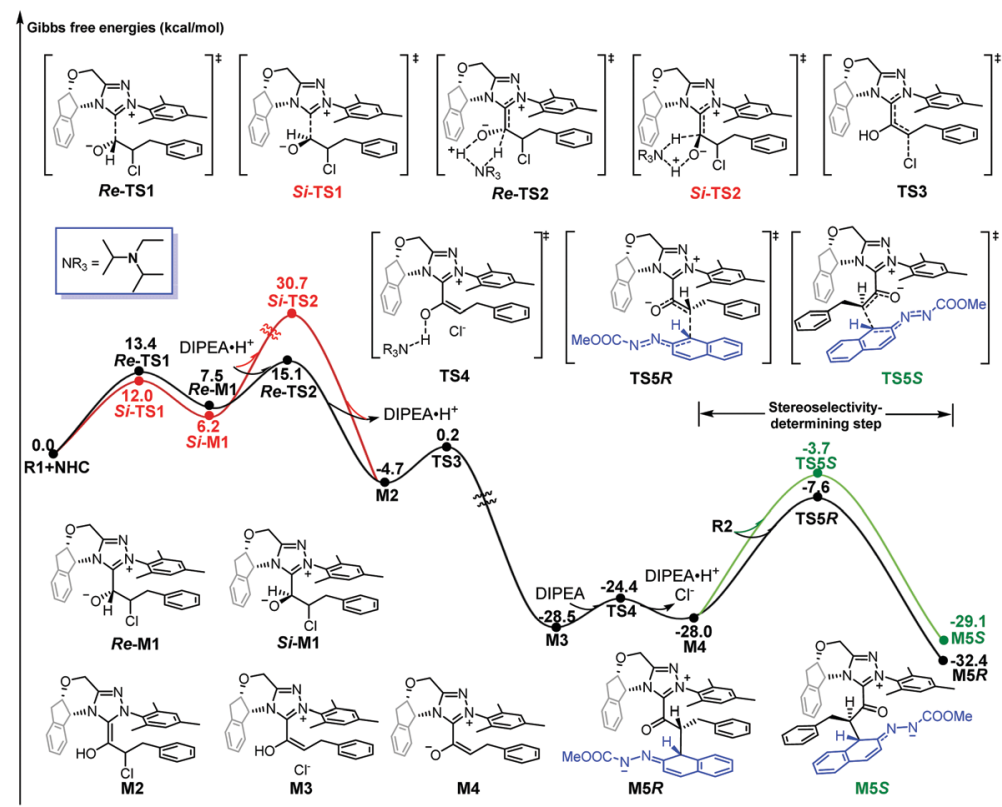

Fig. 1 Relative Gibbs free energy profiles for the adsorption of $\mathrm{NHC}$ and the formation of the $\mathrm{C}-\mathrm{C}$ bond. 
direction, NHC can be divided into $R e$ - and $S i$-faces, and both cases are discussed in more detail in the ESI. $\dagger$ The calculated results show that the energy barrier through transition state $\operatorname{Re}$-TS1 $\left(\Delta G^{\ddagger}=13.4 \mathrm{kcal} \mathrm{mol}{ }^{-1}\right)$ is slightly higher than that through transition state $\operatorname{Si}$-TS1 $\left(\Delta G^{\ddagger}=12.0 \mathrm{kcal} \mathrm{mol}^{-1}\right)$, but the energy barrier of $\operatorname{Re}$-TS2 $\left(\Delta G^{\ddagger}=7.6 \mathrm{kcal} \mathrm{mol}^{-1}\right)$ is much lower than that of $S i$-TS2 $\left(\Delta G^{\ddagger}=24.5 \mathrm{kcal} \mathrm{mol}^{-1}\right)$, so the pathway associated with $R e$-face attack on $\mathbf{R} \mathbf{1}$ by NHC is more energetically favorable. Subsequently, the $\mathrm{C}-\mathrm{Cl}$ bond of Breslow intermediate M2 is cleaved to afford enolate intermediate M3 via transition state TS3 $\left(\Delta G^{\ddagger}=4.9 \mathrm{kcal} \mathrm{mol}^{-1}\right)$. The enolate intermediate M3 can then be easily deprotonated by DIPEA to form acyl azolium intermediate M4 via transition state TS4 $\left(\Delta G^{\ddagger}=4.1 \mathrm{kcal} \mathrm{mol}^{-1}\right)$.

For the stereoselectivity-determining step, the nucleophilic addition of $\mathbf{M} 4$ to azonaphthalene $\mathbf{R} 2$ first undergoes $\mathrm{C}-\mathrm{C}$ bond formation via four diastereoselective transition states TS5RR/ $\boldsymbol{R S} / \boldsymbol{S R} / \boldsymbol{S S}$ to generate intermediates $\mathrm{M} 5 \boldsymbol{R} \boldsymbol{R} / \boldsymbol{R S} / \boldsymbol{S R} / \boldsymbol{S S}$, respectively. As shown in Scheme 2, the two letters after the names represent the molecular chirality associated with the chiral C1 and $\mathrm{C} 2$ atoms, respectively. Inspired by the previous studies, conformational searches of TS5RR/RS/SR/SS were performed to ensure the optimized diastereoselective transition states associated with the lowest energy configurations, and more discussions can be seen in Scheme S3 of the ESI. $\uparrow$ The chiral C2 atom will become the achiral one after the following rearomatization process, so we only selected and discussed TS5RR/SS with the lowest energies to represent TS5R and TS5S (Fig. 1 and 2). The pathway associated with the $R$-configurational product is the energetically favorable pathway, and the energy barrier difference $\left(\Delta \Delta G^{\ddagger}\right)$ between $\Delta G^{\ddagger}$ TS5R and $\Delta G^{\ddagger}$ TS5S is $3.9 \mathrm{kcal} \mathrm{mol}^{-1}$, which corresponds to an enantiomeric excess (ee) value of greater than $99 \%$ according to the equations provided in the ESI, $\dagger$ which is close to the experimental observation (99\% ee). ${ }^{12}$ Atom-inmolecule (AIM) quantitative analysis ${ }^{35}$ (Fig. 2 and Table S1, ESI $\dagger$ ) indicates that a larger number of $\mathrm{C}-\mathrm{H} \cdots \mathrm{O}$ and $\mathrm{C}-\mathrm{H} \cdots \pi$ interactions exist in TS5R than those in TS5S, and these interactions are stronger in the favorable TS5R, so it can be concluded that the $\mathrm{C}-\mathrm{H} \cdots \mathrm{O}$ and $\mathrm{C}-\mathrm{H} \cdots \pi$ interactions are important in controlling the stereoselectivity. It should be mentioned that the energy barrier via TS5R (20.4 $\left.\mathrm{kcal} \mathrm{mol}^{-1}\right)$ can be overcome at room
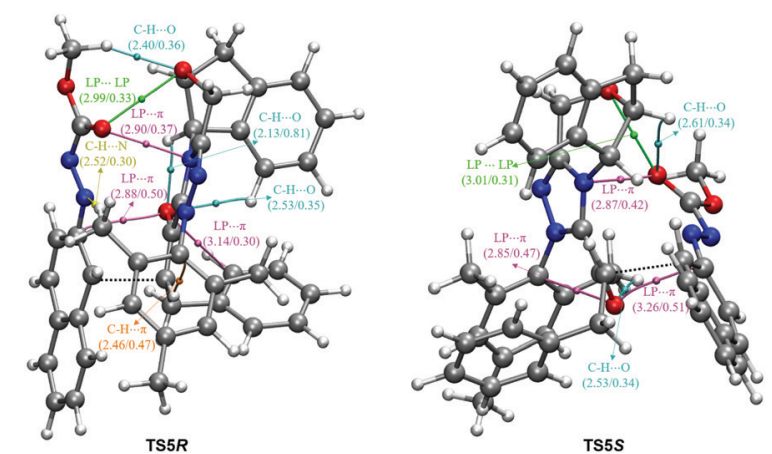

Fig. 2 Quantitative analysis and comparison of the non-covalent interactions involved in TS5R and TS5S (distances in $\AA$ and Laplacian of electron densities in a.u.).

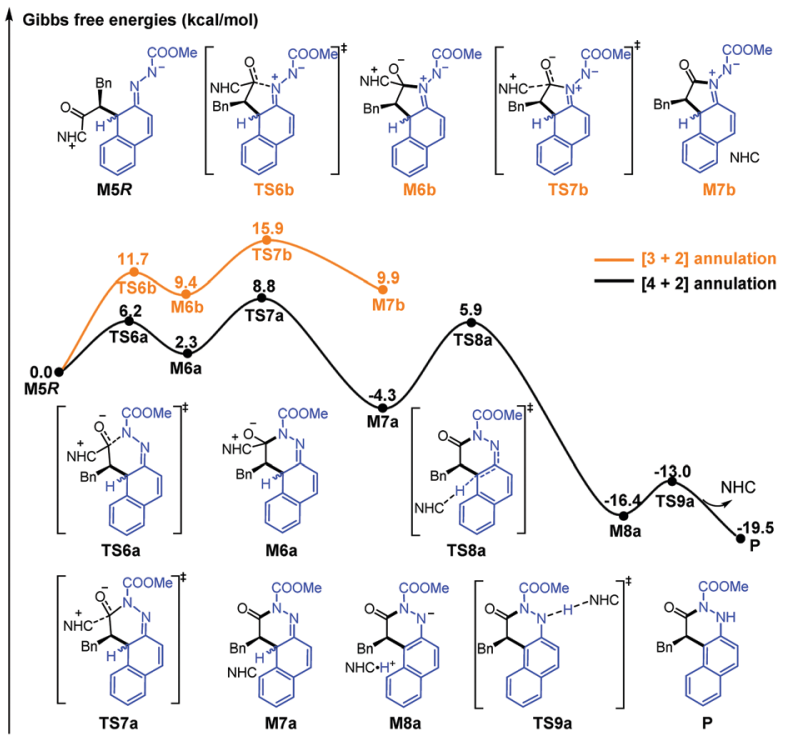

Fig. 3 Relative Gibbs free energy profiles of the most energetically favorable pathways for the possible [3+2] and [4+2] cyclization reactions.

temperature, and the following transformations continue to happen to result in the final product $\mathbf{P}$ depicted in Fig. 3.

Two RC-first and two PT-first mechanisms were then considered for the chemoselective annulation step, and totally more than 16 possible pathways had been considered in this study (see Fig. S5-S8, ESI $\dagger$ ). The highest energy barriers of the best pathways of the RC-first and PT-first mechanisms corresponding to the [4+2] cyclization are 10.2 and $26.7 \mathrm{kcal} \mathrm{mol}^{-1}$, whereas those of the [3+2] cyclization are 15.9 and $21.7 \mathrm{kcal} \mathrm{mol}^{-1}$, respectively. Hence, it should be more favorable for the RC-first mechanism regardless of the formation of the $[3+2]$ or $[4+2]$ cyclization product under NHC catalysis. The most favorable pathways associated with the RC-first mechanism for the [3+2] and $[4+2]$ cyclization reactions are shown and compared in Fig. 3. It can be concluded that the local nucleophilicity of the $\mathrm{N}$ atom close to the ester group is stronger than that of the other $\mathrm{N}$ atom of the azo group (see Table S3 of ESI $\dagger$ ), and thus the $[4+2]$ cyclization occurs more easily. This is also consistent with the experimental observation, ${ }^{12}$ and we only considered the $[4+2]$ cyclization pathway in the following process.

Subsequently, we investigated two types of mechanisms for the rearomatization of intermediate $\mathbf{M 6 a}$, in which the NHC acts as an LB and an MFB (Scheme 2). As shown in Fig. S5 (ESI $\dagger$ ), we found that the energy barrier of the pathway in which NHC acts as an LB is extremely high (37.6 kcal mol $\left.{ }^{-1}\right)$ in the rearomatization process. Therefore, we can safely exclude this pathway. As shown in Fig. 3, ring-closure occurs via TS6a with

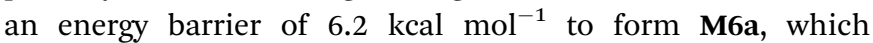
dissociates the NHC to form intermediate M7a via TS7a with an energy barrier of $6.5 \mathrm{kcal} \mathrm{mol}^{-1}$. The in situ generated NHC can act as an MFB to realize $\mathrm{C}\left(\mathrm{sp}^{3}\right)-\mathrm{H}$ deprotonation via TS8a with an energy barrier of $10.2 \mathrm{kcal} \mathrm{mol}^{-1}$, which is followed by final proton transfer for the formation of the final product and regeneration of the NHC catalyst via TS9a with an energy barrier of $3.4 \mathrm{kcal} \mathrm{mol}^{-1}$. Other possible DIPEA-mediated 
deprotonation pathways were also considered and excluded (see the ESI $\dagger$ ). Considering the computational error reported by Singleton and Plata, ${ }^{36}$ we have additionally calculated the proton transfer processes by using different DFT methods and explicit solvents to ensure the reliability of the conclusion, and more details and discussions can be found in part 9 of the ESI. $\dagger$

Although the basicity of NHC should not be weaker than that of the base additive such as DIPEA, ${ }^{37,38}$ NHC is not proposed as the possible $\mathrm{BB}$ catalyst in most of the previous experimental and theoretical studies. Thus, it should be very important to further explore why the transition state has relatively lower energy when the NHC rather than DIPEA abstracts the proton. To uncover this puzzle, the additional NCI analyses on the deprotonation transition state associated with NHC or DIPEA as BB were further performed. As depicted in Fig. S10 of the ESI, $\dagger$ the results indicate that the NHC mainly provides $\mathrm{LP} \cdots \pi$ and $\mathrm{C}-\mathrm{H} \cdots \pi$ interactions to stabilize the deprotonation transition state, and thus we think that NHC should be denoted as a multiple functional base rather than a simple BB in this process. Based on the above results, the NHC should act as an MFB catalyst in the rearomatization process, which is remarkably different from the well-known LB role of NHCs in previous reports.

In summary, the possible reaction mechanisms and selectivities of NHC-catalyzed dearomatization/rearomatization of azonaphthalene with $\alpha$-chloroaldehyde have been systematically investigated by DFT methods. The $\mathrm{C}-\mathrm{C}$ bond formation step is determined to be the stereoselectivity-determining step, and the pathway associated with the $R$-configurational product is predominant in terms of both the kinetics and thermodynamics. According to the energy profiles of different pathways, the RC-first [4+2] annulation pathway is more favorable than the $[3+2]$ annulation pathway. All of the calculated results are in agreement with the experimental results. ${ }^{12}$ Furthermore, AIM analysis shows that $\mathrm{C}-\mathrm{H} \cdots \mathrm{O}$ and $\mathrm{C}-\mathrm{H} \cdots \pi$ interactions are the key factors for controlling the stereoselectivity. Note that the NHC was found to be an MFB in this special case for the first time. The obtained mechanistic insight will guide the understanding of the new role of the NHC catalyst, and thus prompt the development of new NHC catalytic strategies in the future.

Financial support from the National Natural Science Foundation of China (No. 21903072, 21773214, 21822303, and 21772020), the Startup Fund of Zhengzhou University of Light Industry (No. 2017BSJJ036), the Backbone Teacher Project (2020GGJS016), the 111 Project (D20003), and the National Supercomputing Center in Zhengzhou.

\section{Conflicts of interest}

There are no conflicts to declare.

\section{Notes and references}

1 D. A. Colby, R. G. Bergman and J. A. Ellman, Chem. Rev., 2010, 110, 624-655.
2 P. B. Arockiam, C. Bruneau and P. H. Dixneuf, Chem. Rev., 2012, 112, 5879-5918.

3 N. A. Romero, K. A. Margrey, N. E. Tay and D. A. Nicewicz, Science, 2015, 349, 1326-1330.

4 J. B. McManus and D. A. Nicewicz, J. Am. Chem. Soc., 2017, 139, 2880-2883.

5 Y. Liu, Y. L. S. Tse, F. Y. Kwong and Y. Y. Yeung, ACS Catal., 2017, 7, $4435-4440$.

6 L. Qiao, Z. W. Duan, X. N. Wu, D. H. Li, Q. Q. Gu and Y. K. Liu, Org. Lett., 2018, 20, 1630-1633.

7 C. Ma, F. Jiang, F. T. Sheng, Y. Jiao, G. J. Mei and F. Shi, Angew. Chem., Int. Ed., 2019, 58, 3014-3020.

8 L. W. Qi, S. Y. Li, S. H. Xiang, J. Wang and B. Tan, Nat. Catal., 2019, 2, 314-323.

9 L. W. Qi, J. H. Mao, J. Zhang and B. Tan, Nat. Chem., 2018, 10, 58-64.

10 C. Ma, J. Y. Zhou, Y. Z. Zhang, G. J. Mei and F. Shi, Angew. Chem., Int. Ed., 2018, 57, 5398-5402.

11 H. Zhao, H. Yuan, Y. Zhang, R. Li and W. Li, Org. Lett., 2019, 21, 6557-6561.

12 Z. Wu and J. Wang, Chem. Sci., 2019, 10, 2501-2506.

13 Y. Wang, C. Du, Y. Y. Wang, X. K. Guo, L. Fang, M. P. Song, J. L. Niu and D. H. Wei, Adv. Synth. Catal., 2018, 360, 2668-2677.

14 G. J. Wang, Q. Q. Shi, W. Y. Hu, T. Chen, Y. Y. Guo, Z. L. Hu, M. H. Gong, J. C. Guo, D. H. Wei, Z. Q. Fu and W. Huang, Nat. Commun., 2020, 11, 946.

15 X. H. Wang, Y. Wang, J. S. Song and D. H. Wei, Org. Chem. Front., 2020, 7, 1113-1121.

16 Q. Q. Deng, S. J. Li, D. H. Wei and Y. Lan, Org. Chem. Front., 2020, 7, $1828-1836$.

17 S. Li, Z. Tang, Y. Wang, D. Wang, Z. Wang, C. Yu, T. Li, D. Wei and C. Yao, Org. Lett., 2019, 21, 1306-1310.

18 N. Liu, Y. F. Xie, C. Wang, S. J. Li, D. H. Wei, M. Li and B. Dai, ACS Catal., 2018, 8, 9945-9957.

19 Y. Y. Wang, D. H. Wei, Y. Wang, W. J. Zhang and M. S. Tang, ACS Catal., 2016, 6, 279-289.

20 X. Li, J. Xu, S. J. Li, L. B. Qu, Z. J. Li, Y. G. R. Chi, D. H. Wei and Y. Lan, Chem. Sci., 2020, 11, 7214-7225.

21 R. B. Sunoj, Acc. Chem. Res., 2016, 49, 1019-1028.

22 D. Jansen, J. Gramüller, F. Niemeyer, T. Schaller, M. C. Letzel, S. Grimme, H. Zhu, R. M. Gschwind and J. Niemeyer, Chem. Sci., 2020, 11, 4381-4390.

23 T. Niemi, I. Fernández, B. Steadman, J. K. Mannisto and T. Repo, Chem. Commun., 2018, 54, 3166-3169.

24 C. Trujillo, I. Rozas, A. Botte and S. J. Connon, Chem. Commun., 2017, 53, 8874-8877.

25 S.-Y. Zhu, Y. Zhang, X.-F. Chen, J. Huang, S.-H. Shi and X.-P. Hui, Chem. Commun., 2019, 55, 4363-4366.

26 R. C. Samanta, S. De Sarkar, R. Fröhlich, S. Grimme and A. Studer, Chem. Sci., 2013, 4, 2177-2184.

27 S. J. Li, X. Li, H. Mo, L. B. Qu, D. Wei and Y. Lan, Chem. Commun., 2020, 56, 4732-4735.

28 Y. Li, H. Chen, L.-B. Qu, K. N. Houk and Y. Lan, ACS Catal., 2019, 9, 7154-7165.

29 S. Liu, T. Zhang, L. Zhu, F. Liu, R. Bai and Y. Lan, Org. Lett., 2020, 22, 2124-2128.

30 L.-C. Yang, Y.-N. Wang, R. Liu, Y. Luo, X. Q. Ng, B. Yang, Z.-Q. Rong, Y. Lan, Z. Shao and Y. Zhao, Nat. Chem., 2020, 12, 860-868.

31 Y. Zhao and D. G. Truhlar, Acc. Chem. Res., 2008, 41, 157-167.

32 Y. Zhao and D. G. Truhlar, Theor. Chem. Acc., 2008, 120, 215-241.

33 V. Barone and M. Cossi, J. Phys. Chem. A, 1998, 102, 1995-2001.

34 B. Mennucci and J. Tomasi, J. Chem. Phys., 1997, 106, 5151-5158.

35 R. F. W. Bader, Chem. Rev., 1991, 91, 893-928.

36 R. E. Plata and D. A. Singleton, J. Am. Chem. Soc., 2015, 137, 3811-3826.

37 N. Wang, J. Xu and J. K. Lee, Org. Biomol. Chem., 2018, 16, 8230-8244.

38 Z. Li, X. Li and J.-P. Cheng, J. Org. Chem., 2017, 82, 9675-9681. 